\title{
Effects of Recycled Tires Rubber Aggregates on the Characteristics of Cement Concrete
}

\author{
Zeineddine Boudaoud $^{1,2}$, Miloud Beddar ${ }^{1}$ \\ ${ }^{1}$ Laboratory of Materials, Department of Civil Engineering, Faculty of Sciences and Engineering, University of M'Sila, M’Sila, Algeria \\ ${ }^{2}$ Department of Civil Engineering, Faculty of Sciences and Technology, University of Oum El Bouaghi, Oum El Bouaghi, Algeria \\ Email: zboudaoud@yahoo.fr, beddarm@yahoo.fr
}

Received August 30, 2012; revised October 2, 2012; accepted October 16, 2012

\begin{abstract}
This experimental work investigates the impact of substituting part of the conventional aggregates with rubber aggregates on certain characteristics of the cement concretes. This incorporation of rubber aggregates resulting from cutting worn tires in practical sizes decreases the mechanical resistances of the concretes while improving slightly the fluidity of the tested mixtures. The effect of these aggregates on the shrinkage of the concretes at an early age is appreciable and even very interesting for the concretes used, for example, in road construction. This technique of cutting worn tires without any further treatment makes it accessible to everyone which helps not only in saving the environment by getting rid of this cumbersome waste but also in saving traditional aggregates.
\end{abstract}

Keywords: Rubber; Waste Tires; Concrete; Mechanical Response; Shrinkage

\section{Introduction}

The management of worn tires poses a major problem for all third world countries. Also, with the increasing number of vehicles, the industrial development which several countries are currently knowing, and the small percentage of recycled worn tires (retreaded or used for other purposes) due to the absence of an adequate plan for eliminating this waste, these countries know surely a major environmental problem. The absence of statistics on this subject does not enable us today estimate suitably the mass of worn tires thrown in nature or burned in public dumpsters. But if we compare these countries with the European Union countries which took this problem in charge, through legislation, recycling companies, research, we can say that many countries are postponing the solution to this problem, and that the mass of worn tires can only be considerable.

One of the recommended solutions to solve this environmental problem is to incorporate rubber aggregates resulting from cutting worn tires in the cement concretes [1-6]. On this subject, several studies concerning the use of rubber aggregates resulting from crushing worn tires were carried out. These research works showed that the benefits of associating rubber-cement in the development of cementing composites with high deformability [7-9] and on the durability of these composites [10].

Moreover, the benefit which we can gain from using the cement concretes for the roadways makes us think about multiplying the studies on the cement composites that incorporate rubber aggregates since the rigidity of the cement concretes can make it possible either to decrease the granular layer necessary to the asphalt roadway or to allow the use of less resistant concretes. This is the case with the use of concretes having a considerable part of rubber aggregates resulting from worn tires.

With a great ecological concern and in saving traditional aggregates, we have replaced a part of the conventional aggregates by rubber aggregates resulted from cutting worn tires. The study that we propose was realized in two stages, with two different teams, and in two distinct periods of time in order to test the repeatability of certain results and the significance of some factors.

\section{Methodology of the Study}

Various sizes of coarse aggregates and rubber aggregates were used in many studies, and most investigators replaced either the fine or coarse aggregates in the concrete mixes partially or wholly by a volume of rubber aggregate. The size and grading of rubber aggregates used by various investigators varied considerably $[9,11,12]$. In this study, we wanted to test rubber aggregates of forms and sizes different from those used in most of the other studies ecause the size and form of rubber aggregates play a major role in determining the characteristics of the concretes.

The present research study consists of a basic concrete 
(control mix) whose formulation was given by the mean of the Gorisse-Dreux method [13] to replace each time a part of the volume of traditional gravels by rubber aggregates obtained from cutting worn tires without any treatment which makes it accessible to everyone to use (Figure 1).

In the first stage, we achieved from the basic formulation of Table 1 three volumetric substitutions: 5\%, 1\% and $15 \%$ of aggregates $(8 / 16 \mathrm{~mm})$ by rubber aggregates of sizes ranging between 10 and $12 \mathrm{~mm}$. These mixes will be considered as (F1).

In the light of the results obtained from the first stage, we chose a second formulation (Table 2) with the same proportioning of cement but with ratios G/S and W/C higher compared to the first, a more significant aggregate substitution, and with a more spread out granularity and coarser concretes. This time we substituted limestone gravels $(8 / 16)$ and $(16 / 25)$ by rubber aggregates of the two classes: $10 / 12 \mathrm{~mm}$ and $16 / 20 \mathrm{~mm}$. The substitution is always volumetric; it is of: $10 \%, 20 \%$ and $30 \%$. These mixes will be considered as (F2).

All mixtures were mixed in a conventional blade-type mixer where mixing procedures were the same for all concrete mixes. Three slump tests were conducted to assess the workability of the control concrete and the concrete containing rubber aggregates. It is worth mentioning that we measured the shrinkage of all mixtures F2

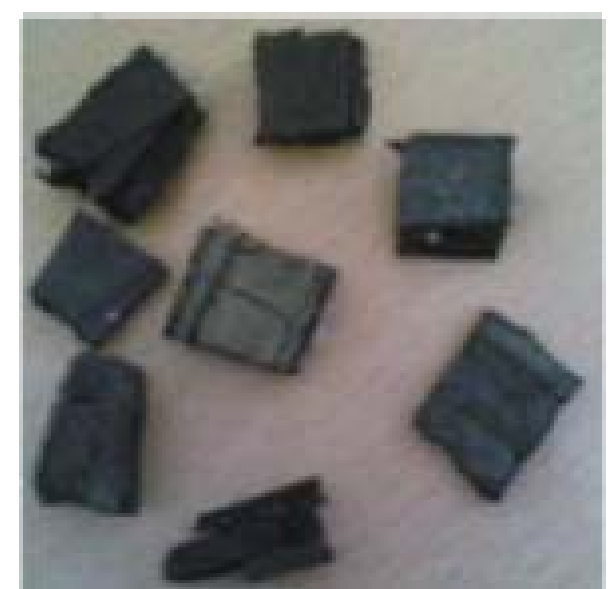

Figure 1. Aggregates rubber used in the study.

Table 1. Mix proportions of first control mix [14].

\begin{tabular}{lcl}
\hline Materials & Quantity $\left(\mathrm{kg} / \mathrm{m}^{3}\right)$ & \\
\cline { 1 - 2 } Dune Sand (0/3 mm) & 536 & \multirow{2}{*}{ Gravel/Sand = 2.22 } \\
Crushed Gravel (3/8 mm) & 259 & \\
Crushed Gravel (8/16 mm) & 933 & \\
Cement CEM II 42.5 & 400 & Water/Cement $=0.51$ \\
Water & 205 & (W/C) \\
\hline
\end{tabular}

Table 2. Mix proportions of second control mix [14].

\begin{tabular}{|c|c|c|}
\hline Materials & Quantity $\left(\mathrm{kg} / \mathrm{m}^{3}\right)$ & \multirow{5}{*}{$\begin{array}{l}\text { Gravel/Sand = } 2.45 \\
(\mathrm{G} / \mathrm{S})\end{array}$} \\
\hline Dune Sand (0/3 mm) & 515 & \\
\hline Crushed Gravel (3/8 mm) & 160 & \\
\hline Crushed Gravel (8/16mm) & 392 & \\
\hline Crushed Gravel (16/25mm) & 710 & \\
\hline Cement CEM II 42.5 & 400 & \multirow{2}{*}{$\begin{array}{l}\text { Water/Cement }=0.55 \\
(\mathrm{~W} / \mathrm{C})\end{array}$} \\
\hline Water & 218 & \\
\hline
\end{tabular}

(with or without rubber aggregate) at different ages (3, 7, 14 and 28 days). The following tests were carried out to establish the mechanical properties of concrete:

- Compressive strength;

- Flexural strength.

\section{Results and Discussion}

\subsection{Entrained Air and Workability}

The incorporation of the rubber aggregates is without effect on the percentage of entrained air (Figure 2). The quantities of entrained air for the tested mixtures remain comparable with the values of the current concretes which vary between $1 \%$ and $2.5 \%$ [15]. On the other hand, most authors reported that when the rubber aggregate was added to the concrete, the content of air increased considerably. They also observed that the content of air increased in concrete mixtures with increasing amounts of rubber aggregates $[11,16,17]$.

The increase in W/C ratio increases the slump of the mixtures regardless of the rubber aggregates' rate in the mixtures. On the other hand, the workability of the mixtures knows a slight improvement with the presence of the rubber aggregates (Figure 3). The shape and the surface of the aggregates resulted from tires (smoother than the traditional gravels) have for sure something to do with this improvement.

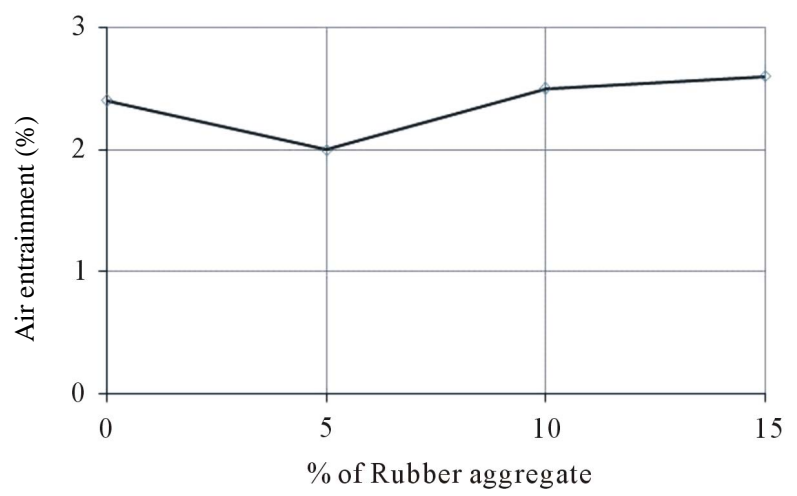

Figure 2. The effect of the substitution rate on the percentage of entrained air of the concretes. 


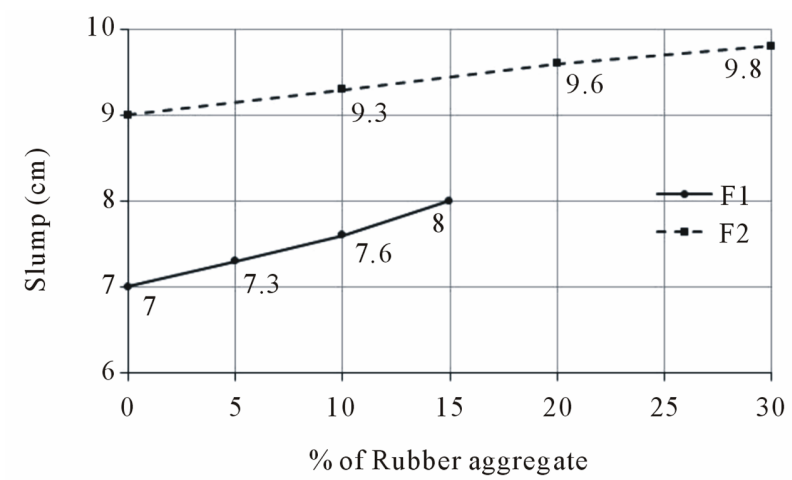

Figure 3. The effect of the substitution rate on the workability of the concretes.

\subsection{Mechanical Resistances}

The compressive and the flexural strengths of concrete specimens were determined after 7 and 28 days of standard curing. Three measurements were taken on cylindrical specimens with a diameter of $16 \mathrm{~cm}$, at height of $32 \mathrm{~cm}$ for compression, and beam specimens of $7 \times 7 \times$ $28 \mathrm{~cm}$ for flexural strength tests. We have noted a dispersion of test results of the various specimens which is due to the nonhomogeneous distribution of rubber aggregates in the concretes.

The flexural and the compressive strengths, according to the incorporation rate in rubber aggregates, are illustrated in Figures 4 and 5. As expected, the mechanical resistances decrease appreciably with the incurporation of rubber aggregates. This decline of mechaniccal resistances is significant as the substitution rate is high.

This work confirms the results of other studies with small sized rubber aggregates [18] and [19]. Even by incorporating fragments of tires of great dimensions in the concretes, Toutanji [20] also noted strong falls of resistances in compression. The defect of adherence between the rubber and the cementing matrix justifies this fall of mechanical resistances. We would have tried to improve this adherence, but according to S. Bonnet [18] even a preliminary chemical treatment of the rubber grains' surface before the mixing, as recommended by certain authors [21,22], would only slightly improve the compressive strengths.

It is noted that the compressive strengths of mixes F2 are higher than F1. This is due to the mixtures workability, the increase in the proportion of gravels in the mixtures, and probably the wide range of aggregate sizes in mixes F2.

The results show also that the addition of rubber aggregates resulted in a significant reduction in compressive and Flexural strengths of concrete compared to the control concrete. This reduction increased with increasing the percentage of rubber aggregate (Figures 6 and 7).

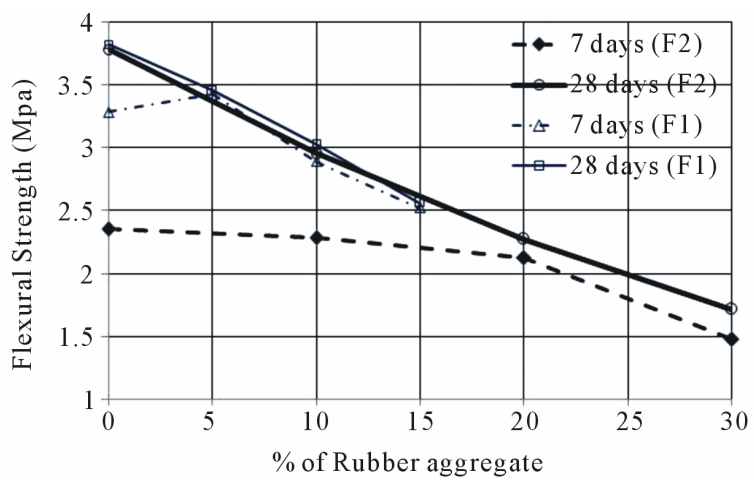

Figure 4. Average of flexural strengths.

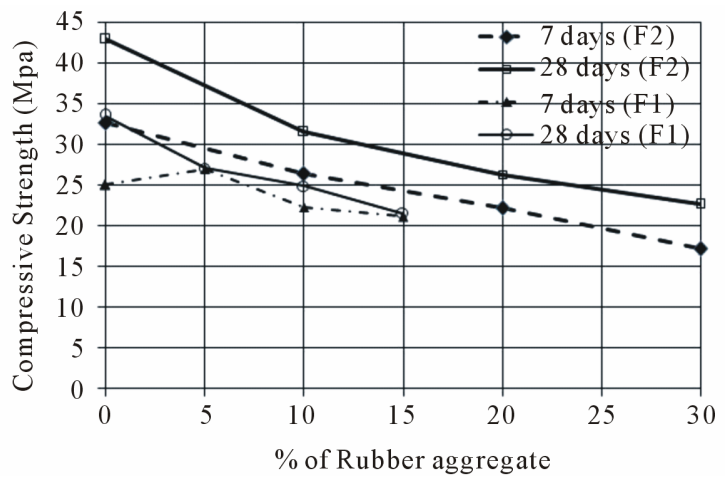

Figure 5. Average of compressive strengths.

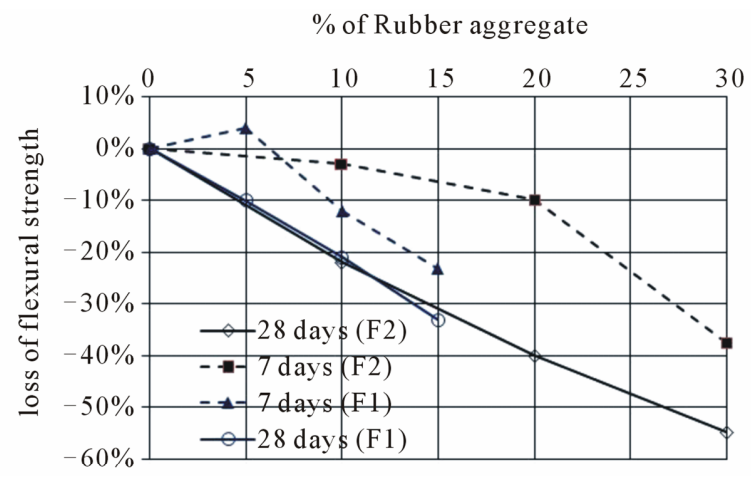

Figure 6. The reduction of flexural strengths.

$\%$ of Rubber aggregate

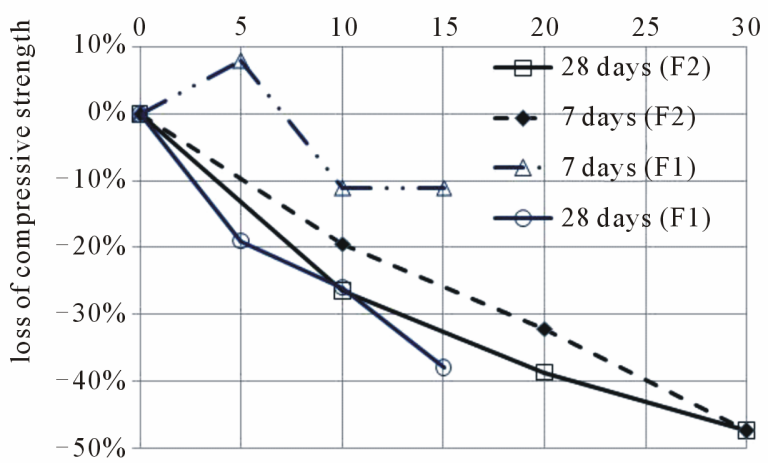

Figure 7. The reduction of compressive strengths. 
It is noted also that, the evolution of resistances in time is not the same for all the tested concretes. The ratio of the compressive strengths at 7 days compared to that of 28 days of the concretes with rubber aggregates is higher than that of the control concrete (Figure 8) and this for the two tested formulations.

\subsection{Drying Shrinkage}

We have taken the measurements according to the time of length variation of beam specimens of concrete preserved in an uncontrolled atmospheric environment (moisture and ambient temperature of the laboratory). The specimens were provided with $20 \mathrm{~cm}$ distant studs, and the measurements were carried out by a retractometer.

The curves of Figure 9 represent the reductions in the dimensional variations of concrete drying shrinkage in relation to the time and rate of substitution in rubber aggregates. We notice that the drying shrinkage of the concretes decreases with the increase in the percentage of rubber aggregates in the concrete. This attenuation of the shrinkage thus of the cracking can improve the durability of these cementing composites. It can be explained by the fact that these composites with rubber aggregates absorb less water and keep for a longer time the heat released during the hydration of cement. Hence, the treatment of concrete through including rubber would be improved. It seems also that these aggregates obstruct the propagation of the microscopic cracks. It is worth mentioning that the numerous they are in the mixtures; the more the effect of these rubber aggregates is felt.

Also, the kinetics of the shrinkage is influenced by the presence of the rubber aggregates. In effect, the shrinkages measured in concrete specimens with inclusions at an early age (3 days) are very weak compared to the shrinkages measured in the control concrete (Figure 7). With time, the relative reduction in the shrinkages decreases a little. Thus, the time and the rate of substitution

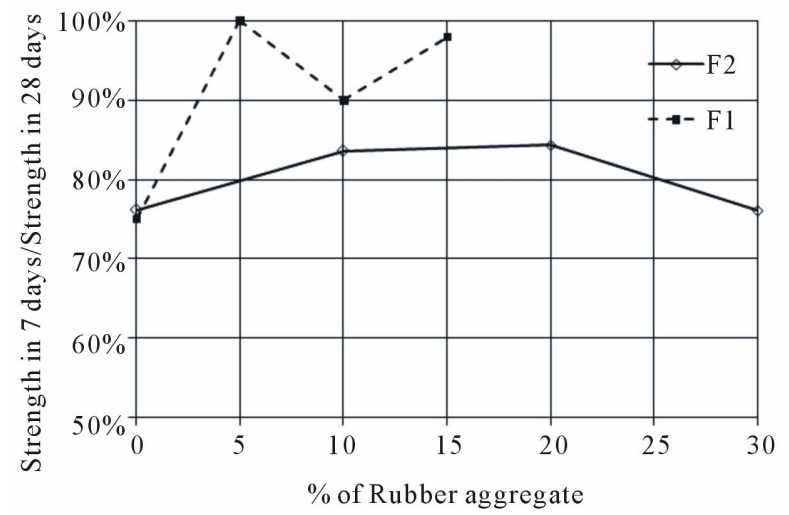

Figure 8. The effect of substitution rate on the evolution of compressive strengths.

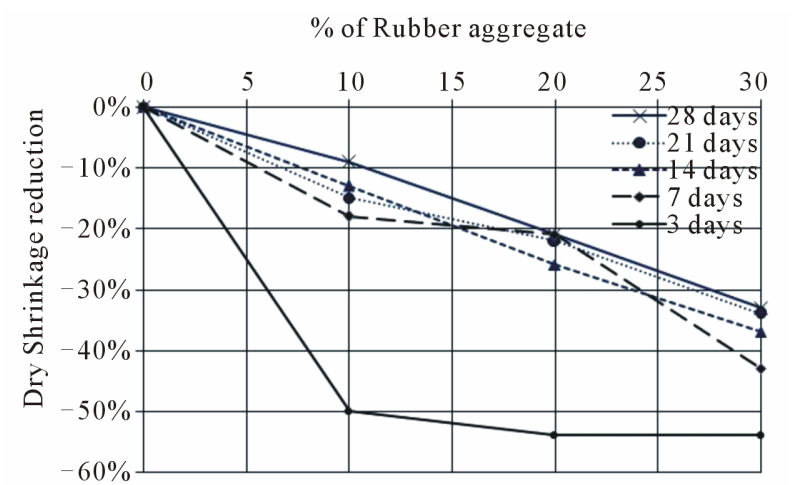

Figure 9. The effect of substitution rate on the shrinkage of concretes.

have a considerable influence on the relative reduction in the shrinkages. Measurements of long-term shrinkage will confirm or reject this report.

\section{Conclusion}

The study of the substitution effects of coarse traditional aggregates by rubber aggregates resulting from worn tires showed a decrease in the mechanical characteristics of the tested concretes. This reduction is proportional to the substitution rate of the aggregates. Nevertheless, the concretes keep a resistance compatible with a possible use in, for example, the road construction industry and offer a substantial economy in the traditional aggregates. Especially, by knowing that the shrinkages measured of these concretes show that the effects of incorporating rubber aggregates are not negligible and encourage the continuation of research in this field. In short, the advantages of substituting parts of the traditional aggregates by others resulting from worn tires proved to be both economic and ecological.

\section{Acknowledgements}

The authors gratefully acknowledge the laboratory staff for their support throughout the making of this study.

\section{REFERENCES}

[1] E. Ganjian, M. Khorami and A. A. Maghsoudi, "ScrapTire-Rubber Replacement Foraggregate and Filler in Concrete," Construction and Building Materials, Vol. 23, No. 5, 2009, pp. 1828-1836. doi:10.1016/j.conbuildmat.2008.09.020

[2] M. K. Batayneh, M. Iqbal and A. Ibrahim, "Promoting the Use of Crumb Rubber Concrete in Developing countries," Waste Management, Vol. 28, No. 11, 2008, pp. 21712176.

[3] I. B. Topcu and A. Demir, "Durability of Rubberized Mortar and Concrete," ASCE Journal of Materials in Civil Engineering, Vol. 19, No. 2, 2007, pp. 173-178. doi:10.1061/(ASCE)0899-1561(2007)19:2(173) 
[4] F. Hernandez-Olivares and G. Barluenga, "Fire Performance of Recycled Rubber-Filled High-Strength Concrete," Cement and Concrete Research, Vol. 34, No. 1, 2004, pp. 109-117. doi:10.1016/S0008-8846(03)00253-9

[5] C. E. Pierce and M. C. Blackwell, "Potential of Scrap Tire Rubber as Lightweight Aggregate Inflowable Fill,” Waste Management, Vol. 23, No. 3, 2003, pp. 197-208.

[6] S. Sgobba, G. C. Marano, M. Borsa and M. Molfetta, "Use of Rubber Particles from Recycled Tires as Concrete Aggregate for Engineering Applications,” Coventry University and The University of Wisconsin Milwaukee Centre for By-Products Utilization, 2nd International Conference on Sustainable Construction Materials and Technologies, Ancona, 28-30 June 2010, 11 p.

[7] A. Benazzouk, K. Mezreb, G. Doyen, A. Goullieux and M. Quéneudec, "Effect of Rubber Aggregates on the Physico-Mechanical Behavior of Cement-Rubber Composites-Influence of the Alveolar Texture of Rubber Aggregates," Cement and Concrete Composites, Vol. 25, No. 7, 2003, pp. 711-720. doi:10.1016/S0958-9465(02)00067-7

[8] A. Benazzouk, O. Douzane and M. Quéneudec, "Transport of Fluids in Cement-Rubber Composites," Cement and Concrete Composites, Vol. 26, No. 1, 2004, pp. 21-29. doi:10.1016/S0958-9465(02)00119-1

[9] U. B. Topçu, "The Properties of Rubberized Concrete," Cement and Concrete Research, Vol. 25, No. 2, 1995, pp. 304-310. doi:10.1016/0008-8846(95)00014-3

[10] A. Benazzouk and M. Queneudec, "Durability of CementRubber Composites under Freeze Thaw Cycles," Proceedings of International congress of Sustainable Concrete Construction, Dundee, September 2002, pp. 355362.

[11] N. A. Ali, A. D. Amos and M. Roberts, "Use of Ground Rubber Tyres in Portland Cement Concrete," Proceedings of International Conference on Concrete, University of Dundee, Dundee, 1993, pp. 379-390.

[12] N. N. Eldin and A. B. Senouci, "Rubber-Tyre Particles as Concrete Aggregate," Journal of Materials in Civil Engineering, Vol. 5, No. 2, 1993, pp. 478-496.
doi:10.1061/(ASCE)0899-1561(1993)5:4(478)

[13] G. Dreux, "Nouveau Guide du Béton,” 3rd Edition, Eyrolles, France, 1981.

[14] Z. Boudaoud, M. Beddar, A. Amroune, A. Yahi, B. Abdelli and C. H. Bourenane, "Rapport Scientifique Interne au Laboratoire de Développement des Géomatériaux,” Université de M’Sila, Algérie, 2008.

[15] J. Baron and J.-P. Ollivier, "Les Bétons. Bases et Données Pour Leur Formulation,” Eyrolles, Paris, 1996.

[16] D. Fedroff, S. Ahmad and B. Z. Savas, "Mechanical Properties of Concrete with Ground Waste Tyre Rubber," Transportation Research Record, Vol. 1532, 1996, pp. 66-72. doi:10.3141/1532-10

[17] Z. K. Khatib and F. M. Bayomy, "Rubberised Portland Cement Concrete," Journal of Materials in Civil Engineering, Vol. 11, No. 3, 1999, pp. 206-213. doi:10.1061/(ASCE)0899-1561(1999)11:3(206)

[18] S. Bonnet, "Effet de l'Incorporation des Granulats Caoutchouc sur la Résistance à la Fissuration,” Des Mortiers, $\mathrm{XXI}_{\text {ème }}$ Rencontres Universitaires de Génie Civil, Prix René Houpert, 2003.

[19] M. Garros, “Composites Cimentaires Incorporant des Granulats Caoutchouc Issus du Broyage de Pneus Usagés: Optimisation de la Composition et Caractérisation,” Ph.D. Thesis, Université Paul Sabatier, Toulouse, 2007.

[20] H. A. Toutanji, "The Use of Rubber Tire Particles in Concrete to Replace Mineral Aggregates,” Cement and Concrete Composites, Vol. 18, No. 2, 1996, pp. 135-139. doi:10.1016/0958-9465(95)00010-0

[21] Z. Li, F. Li and J. S. L. Li, "Properties of Concrete Incorporating Rubber Tyre Particles," Magazine of Concrete Research, Vol. 50, No. 4, 1998, pp. 297-304. doi:10.1680/macr.1998.50.4.297

[22] M. M. Abdel-Wahab and M. E. Abdel-Hameed, "Concrete Using Rubber Tyre Particles as Aggregates," Proceedings of the International Symposium: Recycling and Reuse of Used Tyres, Thomas Telford Ltd., Dundee, 1920 March 2001, pp. 251-259. 